\title{
Characterization of the Mycoplasmalike Organism Associated with Witches'-Broom Disease of Lime and Proposition of a Candidatus Taxon for the Organism, "Candidatus Phytoplasma aurantifolia"
}

\author{
LEYLA ZREIK, PATRICIA CARLE, JOSEPH M. BOVÉ, AND MONIQUE GARNIER* \\ Laboratoire de Biologie Cellulaire et Moléculaire, Institut National de la \\ Recherche Agronomique, 33883 Villenave d'Ornon Cedex, France
}

\begin{abstract}
Witches'-broom disease of small-fruited acid lime (WBDL) is a severe disease caused by a mycoplasmalike organism (MLO) in the Sultanate of Oman and the United Arab Emirates. The WBDL MLO was characterized by studying its genome size, the sequences of its 16S ribosomal DNA and the 16S-23S ribosomal DNA spacer region, and hybridization profiles obtained by using WBDL MLO-specific probes. The size of the WBDL MLO genome is $720 \mathrm{kbp}$. Genomic similarities with the MLOs of sunhemp, sesame, and alfalfa phyllodies were demonstrated, and we found that the WBDL MLO belongs to the sunhemp phyllody phylogenetic subgroup.
\end{abstract}

Witches'-broom disease of small-fruited acid lime [Citrus aurantifolia (L.) Swingle] (WBDL) is a lethal disease which is caused by a mycoplasmalike organism (MLO) and appeared in the Sultanate of Oman in the late $1970 \mathrm{~s}(2,3,7)$ and in the neighboring country the United Arab Emirates in $1989(4,7)$. The WBDL MLO was experimentally transmitted by dodder (Cuscuta campestris Yunker) to periwinkle (Catharantus roseus L.) plants, in which it induces characteristic symptoms different from those reported with other MLOs (7). The WBDL MLO is thought to be naturally spread by the leafhopper Hishimonus phycitis, as many WBDL MLO-infected $H$. phycitis individuals were collected from lime trees with WBDL in Oman (4). However, experimental transmission of the disease with $H$. phycitis has not been achieved yet. Widely spread in India, $H$. phycitis was not reported from the Arabic Peninsula (5) before we found it there (4). As lime trees have been grown in Oman for centuries, it is likely that the disease started with the introduction of this new insect vector, probably from India, where it is known to transmit the MLO of eggplant little-leaf disease (1). The MLO agent, however, was probably indigenous to the Sultanate of Oman since the disease has never been described in India or elsewhere.

In 1991, monoclonal antibodies and DNA probes specific for the WBDL MLO were produced (7). No serological relationships with any of the other MLOs tested, including the eggplant little-leaf disease MLO from India, were detected, but in this paper we show that DNA extracted from phyllody MLOinfected sunhemp, sesame, and alfalfa plants hybridized with the DNA probes which we tested.

In order to determine the phylogenetic position of the WBDL MLO among the mollicutes, we cloned and sequenced its 16S rRNA gene. Indeed, even though MLOs cannot be cultured, their phylogenic positions have been determined from the sequences of their $16 \mathrm{~S}$ ribosomal DNAs (rDNAs) $(10$, $11,15,19)$. These organisms have been shown to be true mollicutes, and the name "phytoplasma" has been proposed for them (20). In addition, the sequence of the 16S-23S rDNA spacer region and the genome size of the WBDL MLO were determined.

* Corresponding author. Mailing address: Laboratoire de Biologie Cellulaire et Moléculaire, Institut National de la Recherche Agronomique, B.P. 81, 33883 Villenave d'Ornon Cedex, France.
(A preliminary account of the results has been published previously [4].)

\section{MATERIALS AND METHODS}

Plant material. Healthy periwinkle and lime plants were obtained from seeds and were maintained at $25^{\circ} \mathrm{C}$ during the day and at $20^{\circ} \mathrm{C}$ at night.

Lime and periwinkle plants were infected with the WBDL MLO by graft transmission and were grown in a greenhouse at $30^{\circ} \mathrm{C}$ during the day and at $25^{\circ} \mathrm{C}$ at night.

Periwinkle plants infected with the MLOs of apple proliferation, aster yellows, clover phyllody, cabbage chloranty, eggplant little-leaf, and tomato stolbur diseases were obtained from our MLO collection; plants exhibiting symptoms of sesame phyllody and sunhemp phyllody were obtained from E. Seemüller (Heidelberg, Germany); and alfalfa plants exhibiting phyllody symptoms were collected in the Sultanate of Oman in February 1992 by A. M. M. Mjeni and were sent to Bordeaux, France.

WBDL MLO-specific probes. Production of probes P1 (I1H) and P3 (I10H) has been described previously (7).

Extraction of DNA from plants. Crude nucleic acids were extracted from plants as described by Grawel and Jarret (8).

Southern blot hybridization. Portions ( 5 to $10 \mu \mathrm{g}$ ) of DNAs extracted from healthy or infected plants were digested with a restriction endonuclease, electrophoresed in $0.7 \%$ agarose gels, and transferred to nylon $\mathrm{N}^{+}$membranes (Amersham) (17). The preparations were hybridized overnight at $42^{\circ} \mathrm{C}$ and then washed three times at room temperature in $2 \times \mathrm{SSC}-0.5 \%$ sodium dodecyl sulfate (SDS) ( $1 \times \mathrm{SSC}$ is $0.15 \mathrm{M} \mathrm{NaCl}$ plus $0.015 \mathrm{M}$ sodium citrate) and once at $55^{\circ} \mathrm{C}$ in $0.1 \times$ SSC $-0.1 \%$ SDS. Each membrane was then exposed to X-ray film at $-70^{\circ} \mathrm{C}$ by using enhancer screens.

PCR amplification of 165 rDNA. Approximately $1 \mu \mathrm{g}$ of DNA from healthy or WBDL MLO-infected periwinkle plants was digested with $5 \mathrm{U}$ of restriction endonuclease $B c l$ I (GIBCO/BRL) in a total volume of $20 \mu \mathrm{l}$. A 10-ng portion of the resulting restricted DNA was used as a PCR template with primers fd1 and rp1 (21), which are known to amplify almost the entire 16S rRNA gene of prokaryotes.

Amplification was performed in a $50-\mu$ l reaction mixture containing each of the deoxynucleoside triphosphates at a concentration of $125 \mu \mathrm{M}$, each of the primers at a concentration of $0.5 \mu \mathrm{M}$, and $2.5 \mathrm{U}$ of $T a q$ polymerase (GIBCO/ BRL). The PCR conditions were as follows: 30 cycles consisting of $1 \mathrm{~min}$ at $95^{\circ} \mathrm{C}$ $1 \mathrm{~min}$ at $53^{\circ} \mathrm{C}$, and $1 \mathrm{~min}$ at $72^{\circ} \mathrm{C}$, plus an additional cycle with a 10 -min chain elongation step. All amplifications were performed with a thermocycler apparatus (Perkin-Elmer Cetus).

Amplified DNA was analyzed by electrophoresis on a $1 \%$ agarose gel before and after digestion with restriction enzymes EcoRI and $B c l$ I.

Amplification of the 16S-23S rDNA spacer region. To amplify the $16 \mathrm{~S}-23 \mathrm{~S}$ rDNA spacer region, we used primer P7 (9) and primer WB3, which was determined from the sequence of the WBDL MLO 16S rDNA (positions 434 to 455 ). Amplification was performed as described above by using DNA extracted from WBDL MLO-infected periwinkle plants as the template.

DNA sequencing. PCR-amplified 16S rDNA from the WBDL MLO was cloned in pUC18 (GIBCO/BRL) by using standard procedures. Both strands of the DNA fragment were sequenced by using a T7 polymerase kit (Pharmacia). We used two universal primers that primed near the multiple cloning site of the 
TABLE 1. Designations of the MLOs used in this study and accession numbers of their $16 \mathrm{~S}$ rDNA sequences

\begin{tabular}{llc}
\hline MLO designation & \multicolumn{1}{c}{ Origin } & Accession no. \\
\hline AAY & American aster yellows & X68373 \\
ACLR & Apricot chlorotic leaf roll & X68338 \\
AT & Apple proliferation & X68375 \\
ASHY & Ash yellow & X68339 \\
BAWB & Rhamnus frangula & X76431 \\
BVK & Leafhopper borne & X76429 \\
FD & Flavescence dorée & X76560 \\
JGr1 & Onion yellows & D12569 \\
JGr2 & Tsuwabuki witches' broom & D12580 \\
JGr3 & Rice yellow dwarf & D12581 \\
OAY & Virescence of Oenothera hookeri & M30790 \\
PPER & Stone fruit yellow of peach & X68374 \\
SCWL & Sugar cane white leaf & X76432 \\
Stol & Stolbur of Capsicum annuum & X76427 \\
SunH & Sunhemp phyllody & X76433 \\
Vac & Witches' broom of Vaccinium myrtilus & X76430 \\
VK & Vitis vinifera & X76428 \\
WX & Western-X disease & L04682 \\
WBDL & Witches' broom of lime & U15442 \\
\hline
\end{tabular}

vector and two internal primers, WB1 and WB2, which were designed in the $16 \mathrm{~S}$ rDNA of the WBDL MLO and extended from position 331 to position 350 and from position 1120 to position 1139 , respectively.

Data analysis. The sequences of the WBDL MLO DNA were aligned with the sequences of other microorganisms. The sequences of the other microorganisms were obtained from GenBank by using the retrieve program of the National Center for Biotechnology Information, National Library of Medicine, National Institutes of Health, Bethesda, Md. The 16S rDNA sequences used in this study were the $16 \mathrm{~S}$ rDNA sequences of Bacillus subtilis, Spiroplasma citri, and the MLOs listed in Table 1.

Multiple alignments were examined by using the CLUSTAL software. Distance matrix and phylogenetic trees were constructed with the PHYLIP version 3.5 software package by using the least-squares method of Fitch and Margoliash (6).

Preparation of plant samples for pulsed-field gel electrophoresis. Tissue extracts from healthy and WBDL MLO-infected periwinkle plants were fractionated by differential centrifugation as described by Neimark and Kirkpatrick (16). The final pellet was suspended in STE buffer $(100 \mathrm{mM} \mathrm{NaCl}, 10 \mathrm{mM}$ Tris- $\mathrm{HCl}$ [pH 7.5], $1 \mathrm{mM}$ EDTA) and mixed with an equal volume of molten $2 \%$ lowmelting-point agarose in STE buffer. The mixture was poured into molds, and after solidification the agarose blocks were incubated for 2 days at $50^{\circ} \mathrm{C}$ in lysis buffer (10 mM Tris-HCl [pH 9.5], $0.5 \mathrm{M}$ EDTA, $1 \%$ Sarkosyl [ $\mathrm{N}$-lauroyl sarcosine, sodium salt], $1 \mathrm{mg}$ of proteinase $\mathrm{K}$ per $\mathrm{ml}$ ). The blocks were then placed in sterile TE (10 mM Tris, $1 \mathrm{mM}$ EDTA; $\mathrm{pH} 8)$ and cooled on ice. Degraded DNA was removed from the blocks by transverse alternative field electrophoresis in $1 \% \mathrm{LE}$ agarose under the following conditions: $370 \mathrm{~mA}$; three steps $(12 \mathrm{~h}$ each); and pulses of 1,2 , and $3 \mathrm{~min}$. Transverse alternative field electrophoresis was performed with a Geneline II apparatus (Beckman Instruments, Inc., Palo Alto, Calif.). The blocks were then removed from the gel and irradiated for $3 \mathrm{~min}$ with a ${ }^{137} \mathrm{Cs}$ gamma ray source (irradiator type IBL 337; Oris) at a dose of 5.17 $\mathrm{Gy} / \mathrm{min}$. The blocks were then subjected to electrophoresis in $0.9 \% \mathrm{LE}$ agarose under the following conditions: $370 \mathrm{~mA}$ and four steps, which lasted $8.5 \mathrm{~h}, 3.75$ $\mathrm{h}, 12 \mathrm{~h} 1 \mathrm{~min}$, and $4 \mathrm{~h} 2 \mathrm{~min}$. The DNA in the gels was stained with ethidium bromide, and the sizes of the bands were determined by comparison with a yeast chromosomal DNA size marker (215 to 2,200 kbp; Bio-Rad, Richmond, Calif.) electrophoresed under the same conditions.

Southern blot analysis of the WBDL phytoplasma chromosome. The agarose gel after pulsed-field gel electrophoresis was transferred onto a nylon $\mathrm{N}^{+}$membrane (Amersham) by a standard Southern blotting procedure (17). To facilitate transfer of the large DNA molecule from the gel, the DNA was depurinated by soaking it twice in $0.25 \mathrm{M} \mathrm{HCl}$ for $10 \mathrm{~min}$. Hybridization with probe P3 was performed as described above.

Nucleotide sequence accession numbers. The sequence of the WBDL MLO $16 \mathrm{~S}$ rDNA and the 16S-23S rDNA spacer region has been deposited in the GenBank database under accession number U15442. The GenBank accession numbers of the 16S rDNA sequences of $B$. subtilis and $S$. citri are X60646 and M23942, respectively. The GenBank accession numbers of the $16 \mathrm{~S}$ rDNA sequences of MLOs used in this study are shown in Table 1. The EMBL accession number of the $16 \mathrm{~S}-23 \mathrm{~S}$ rDNA spacer region of the flavescence dorée MLO is $\mathrm{X} 76560$.

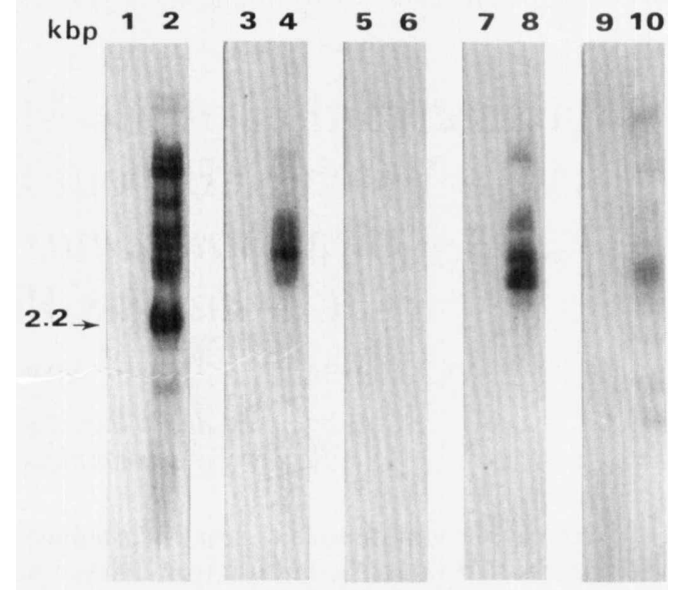

FIG. 1. Southern blot hybridization between probe P3 and HindIII-digested DNAs extracted from healthy periwinkle (track 1), sesame (track 3), eggplant (track 5), sunhemp (track 7), and alfalfa (track 9) plants or from the same plants infected with the MLOs of WBDL (track 2), sesame phyllody (track 4), eggplant little-leaf disease (track 6), sunhemp phyllody (track 8 ), and alfalfa phyllody (track 10).

\section{RESULTS}

Southern hybridizations with probes $\mathbf{P 1}$ and P3. Probes P1 and P3 were obtained by cloning WBDL MLO DNA-enriched preparations as described previously (7). Figure 1 shows the results of Southern hybridizations between probe P3 and HindIII-restricted DNAs extracted from healthy periwinkle (track 1), sesame (track 3), eggplant (track 5), sunhemp (track 7), and alfalfa (track 9) plants or from similar plants infected with the MLOs of WBDL (track 2), sesame phyllody (track 4), eggplant little-leaf disease (track 6), sunhemp phyllody (track 8 ), and alfalfa phyllody (track 10 ). Track 2 shows that the probe recognized multiple restriction fragments in the homologous WBDL MLO genome; the size of the major fragment was $2.2 \mathrm{kbp}$ and thus was identical to the size of the cloned P3 insert, as expected. All of the other MLO DNAs except the DNA of eggplant little-leaf disease MLO (track 6) hybridized with the probe; however, the hybridization profiles were different from the profile of the homologous hybridization preparation shown in track 2; in particular, the $2.2-\mathrm{kbp}$ band was absent. Hybridization with the alfalfa phyllody MLO was relatively weak. No hybridization was detected with DNAs from uninfected plants (tracks $1,3,5,7$, and 9).

Similar results were obtained with probe $\mathrm{P} 1$, which hybridized with a $0.8-\mathrm{kbp}$ fragment of the WBDL MLO genome. DNAs from the phyllody MLO-infected sesame and sunhemp plants hybridized with the probe, but the size of the fragment found in the restricted genomes of these organisms was about $2.4 \mathrm{kbp}$; these results reflected DNA polymorphism, as the probe P3 results did. Again, no hybridization was observed with healthy plant DNAs or DNA extracted from eggplants infected with the eggplant little-leaf disease MLO. The two probes were tested with 10 additional MLO-infected plant DNAs (see Materials and Methods) (4), and no hybridization was detected in any of these preparations.

Genome size of the WBDL MLO. When healthy or WBDL MLO-infected periwinkle preparations obtained as described in Materials and Methods were subjected to gamma ray irradiation and analyzed by pulsed-field gel electrophoresis, degraded DNA was observed in the lower half of the gel, and this DNA interfered with the detection of a putative MLO DNA band by hybridization with probe P3 (data not shown). How- 


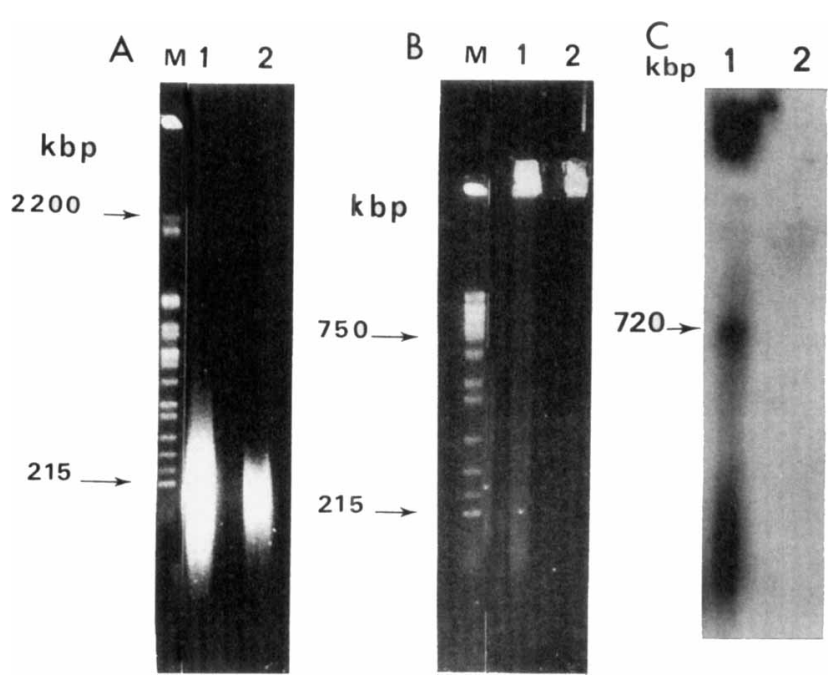

FIG. 2. (A and B) Pulsed-field gel electrophoresis of DNAs extracted from healthy (tracks 2) or WBDL MLO-infected (tracks 1) periwinkle plants before (A) and after (B) gamma ray irradiation. (C) Southern blot of the gel shown in panel $B$ after hybridization with probe $\mathrm{P} 3$.

ever, degraded DNA could be eliminated before irradiation by electrophoresis. The results of this step are shown in Fig. 2A for WBDL MLO-infected (track 1) and healthy (track 2) extracts. Degraded DNA was observed in both extracts. After this preliminary electrophoresis step, the blocks containing the extracts were excised from the gel, irradiated, and used for a second gel migration. The resulting stained gels are shown in Fig. 2B. Only a little degraded DNA was left, but no DNA band was observed in the track containing the MLO-infected extract (track 1). However, after the gel was transferred onto a nylon membrane, hybridization with probe $\mathrm{P} 3$ revealed a 720 kbp DNA band in the extract obtained from WBDL MLOinfected periwinkle plants (Fig. 2C, track 1). As expected, no hybridization was observed in the track containing healthy periwinkle extracts (track 2).

Amplification, cloning, and sequencing of WBDL MLO 16S rDNA. It is known from previous studies that the 16S rDNA of periwinkle chloroplasts can be hydrolyzed by restriction enzyme $B c l$ I but not by EcoRI and that, inversely, MLO $16 \mathrm{~S}$ rDNA is not sensitive to $B c l$ l but is sensitive to EcoRI (18). Figure 3 shows the results of PCR amplification of $B c l$ I-digested DNAs from healthy (track 2) and WBDL MLO-infected (track 5) periwinkle plants; these results were obtained by using universal primers to amplify prokaryotic $16 \mathrm{~S}$ rDNA (21). In both cases, a DNA band was observed at about $1.5 \mathrm{kbp}$, showing that digestion of chloroplast $16 \mathrm{~S}$ rDNA by $B c l$ I was not complete. After the amplified DNA was digested by EcoRI (tracks 3 and 6) or BclI (tracks 4 and 7), the amplified DNA from healthy periwinkle plants was not digested by $E c o$ RI (track 3 ) but was digested by $B c l$ I into two fragments (1.25 and $0.25 \mathrm{kbp}$ ) (track 4). Two different DNAs were present in the DNA amplified from WBDL MLO-infected periwinkle plants; one of these DNAs could be hydrolyzed by BclI (track 7) and corresponded to chloroplast $16 \mathrm{~S}$ rDNA, and one yielded two fragments $(0.85$ and $0.65 \mathrm{kbp})$ after digestion with EcoRI (track 6). This DNA was probably the WBDL MLO DNA.

The DNA amplified from WBDL MLO-infected periwinkle plants was cloned in pUC18, and recombinant plasmids likely to contain MLO $16 \mathrm{~S}$ rDNA inserts on the basis of their sensitivity to EcoRI were selected and sequenced. In order to verify that the sequenced DNA was indeed the WBDL MLO

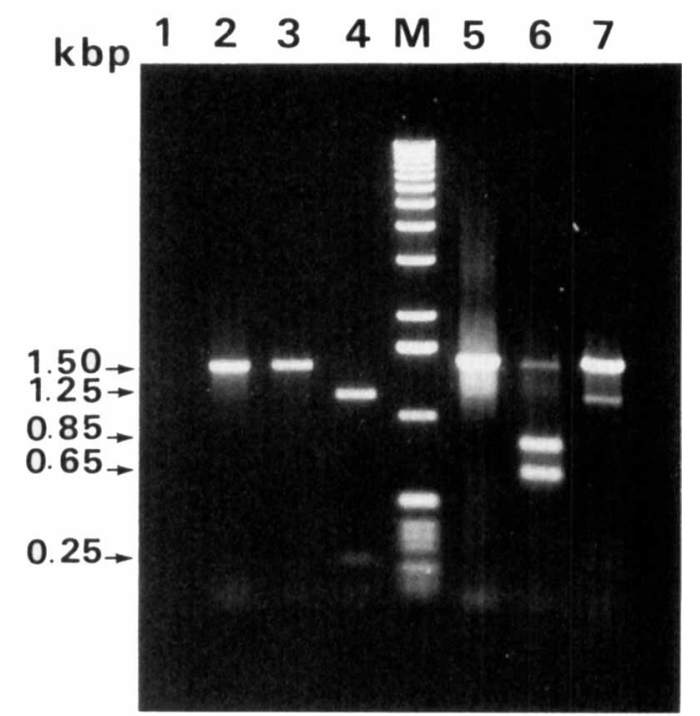

FIG. 3. Agarose gel electrophoresis of DNA amplified by PCR with universal primers for the amplification of prokaryotic 16S rDNA from water (track 1) and $B c l I-d i g e s t e d$ DNAs from healthy (track 2) and WBDL MLO-infected (track 5) periwinkle plants. The DNAs in tracks 2 and 5 were digested with EcoRI (tracks 3 and 6 , respectively) and with $B c l I$ (tracks 4 and 7 , respectively). Track M contained a 1-kb ladder (GIBCO/BRL).

DNA, internal primer WB3, which was deduced from this sequence, was used in combination with universal primer rp1 to amplify $16 \mathrm{~S}$ rDNAs from plants infected with various MLOs. A fragment of the expected size $(1 \mathrm{kbp})$ was amplified from periwinkle or lime plants infected with the WBDL MLO but not from healthy periwinkle or lime plants or periwinkle plants infected with the MLOs of eggplant little-leaf, tomato stolbur, apple proliferation, cabbage chloranty, and clover phyllody diseases. Oligonucleotide WB3 was also checked for possible homology with other prokaryotic $16 \mathrm{~S}$ rDNA sequences by using the "check probe" option of the Ribosomal Database Project program (13). We found no homology with any other sequence in the data bank.

A phylogenetic tree was constructed after the WBDL MLO 16S rDNA sequence was compared with the sequences of other MLOs in GenBank database (Fig. 4). This tree shows that the WBDL MLO clusters with the other MLOs which we studied and is closely related to the sunhemp phyllody MLO, as expected from our hybridization data and from the high level of sequence homology of the 16S rDNAs of these organisms $(97.53 \%)$. Finally, primer WB3 was used in combination with primer $\mathrm{rp} 1$ to amplify DNA extracted from phyllody MLO-infected sunhemp, sesame, and alfalfa plants. The results are shown in Fig. 5. A DNA band was observed with all three MLOs (Fig. 5, tracks 6 through 8), and the position of the band (1 kbp) was identical to the position of the band obtained with DNA extracted from WBDL MLO-infected periwinkle (track 4) or lime (track 5) plants.

Sequence of the 16S-23S rDNA spacer region. A 1,368-bp fragment was amplified with the primers P7 and WB3. This fragment was cloned and sequenced. The sequence showed that the fragment contained in addition to the $5^{\prime}$ end of the $16 \mathrm{~S}$ rDNA and the $3^{\prime}$ end of the 23S rDNA the 16S-23S rDNA spacer region of WBDL MLO. This spacer region is $223 \mathrm{bp}$ long and includes the gene for one of the three tRNA ${ }^{\text {Ile }}$ residues (anticodon, GAT). The same tRNA ${ }^{\text {Ile }}$ gene sequence has been found previously in the $16 \mathrm{~S}-23 \mathrm{~S}$ rDNA spacer regions of the three MLOs tested, the aster yellows (9), flavescence 


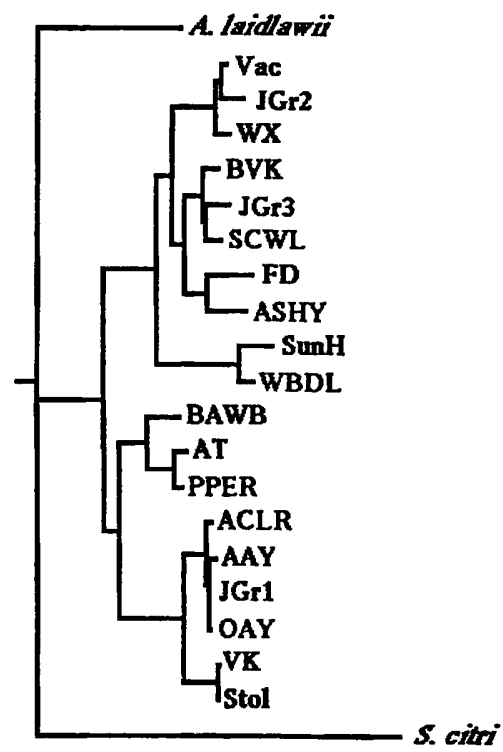

FIG. 4. Phylogenetic tree constructed with the sequences of $16 \mathrm{~S}$ rDNAs obtained from GenBank. MLO designations are explained in Table 1.

dorée, and Oenothera hookeri MLOs (11). The level of sequence homology for the 76 nucleotides encoding the tRNA ${ }^{\text {Ile }}$ gene in the four MLOs is $100 \%$. In contrast, the sequences flanking the tRNA ${ }^{\text {Ile }}$ gene in the WBDL MLO spacer region are not homologous to the sequences of the other three MLOs. In addition, the WBDL MLO sequence upstream of the tRNA gene has a deletion of 38 nucleotides compared with the same region in the aster yellows MLO and a deletion of 28 nucleotides compared with the same region in the flavescence dorée MLO.

\section{DISCUSSION}

WBDL is a disease which appeared recently on small-fruited acid lime trees in the Arabic Peninsula (Sultanate of Oman and the United Arab Emirates). This disease has not been found in any other citrus-growing country.

Characterization of the MLO associated with WBDL shows that the agent has a $720-\mathrm{kbp}$ genome. This small genome size

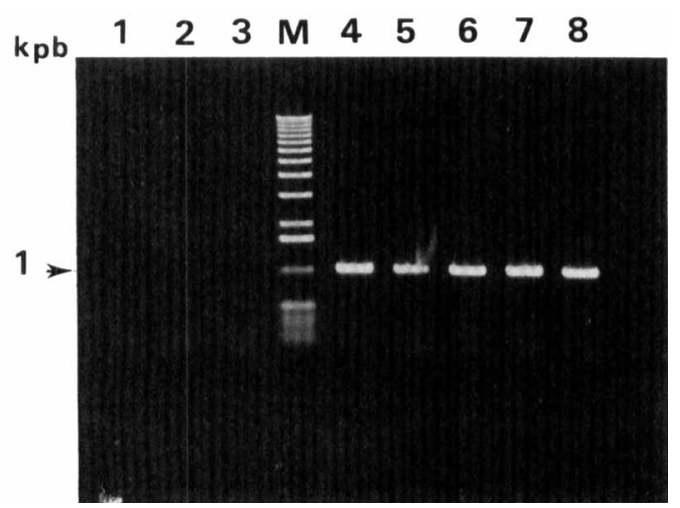

FIG. 5. Agarose gel electrophoresis of DNA amplified by PCR with primers rp1 and WB3 from water (track 1), DNAs extracted from healthy (tracks 2 and 3 ) and WBDL MLO-infected (tracks 4 and 5) periwinkle (tracks 2 and 4) and lime (tracks 3 and 5) plants, and DNAs extracted from phyllody MLO-infected sunhemp (track 6), sesame (track 7), and alfalfa (track 8) plants. Track M contained a 1-kb ladder (GIBCO/BRL). is in the range of the genome sizes of other mollicutes and MLOs $(12,16)$. The genome band could not be detected after direct pulsed-field gel electrophoresis of total DNA extracted from infected periwinkle plants for the following two major reasons: (i) MLOs are located in the phloem, WBDL results in a reduction in the phloem tissue, and hence the titer of the MLO in the plant is low, resulting in a low proportion of MLO DNA compared with plant DNA; and (ii) during Southern hybridization degraded MLO DNA produces a hybridization smear which masks the undegraded MLO genome. These difficulties could be overcome by subjecting the total DNA to a preliminary electrophoresis step which eliminated most of the degraded DNA. The sequential electrophoresis technique which we used might be useful for determinations of the chromosome sizes of other MLOs.

Our phylogenetic studies of 16S rDNA sequences showed that the WBDL MLO clusters with the sunhemp phyllody MLO. This result is consistent with our hybridization results, in which DNA from sunhemp phyllody MLO hybridized with the WBDL MLO probes. However, we have clearly established by serological (7) and molecular (this paper) studies that the WBDL MLO is different from the sunhemp MLO, probably at the species level since the level of homology of the $16 \mathrm{~S}$ rDNAs of these organisms is only $97.53 \%$. The alfalfa and sesame phyllody MLOs are also closely related to the WBDL MLO since (i) their DNAs hybridize with WBDL MLO probes, even though Southern hybridization profiles exhibit polymorphism, and (ii) their 16S rDNAs could be amplified with primer WB3, a primer based on the WBDL MLO 16S rDNA sequence. For these reasons the MLOs of WBDL and of sunhemp, alfalfa, and sesame phyllodies are members of the same phylogenetic subgroup. We also found that the 16S-23S rDNA spacer region of the WBDL MLO includes a tRNA ${ }^{\text {Ile }}$ gene identical to that present in the spacer regions of the three MLOs in which this region has been studied. However, the sequences flanking the tRNA gene are highly variable and will undoubtedly provide a way to distinguish different MLOs belonging to the same subgroup.

It has been clearly established that MLOs are true mollicutes, and the name "Phytoplasma" has been proposed recently by the Subcommittee on the Taxonomy of Mollicutes (20). Furthermore, Murray and Schleifer have proposed a way to record the properties of putative taxa of prokaryotes, including uncultured organisms (14). For these reasons, we propose giving the WBDL MLO a Candidatus name with the following description: "Candidatus Phytoplasma aurantifolia" [(Mollicutes) NC; NA; O; NAS (GenBank number U15442), oligonucleotide sequence complementary to unique region of 16S rRNA 5'-GCAAGTGGTGAACCATTTGTTT-3'; S (Citrus, phloem; Hishimonus phycitis (Cicadellidae), hemolymph, salivary glands); M].

\section{REFERENCES}

1. Bindra, O. S., and A. S. Sohi. 1968. Host range of Hishimonus phycitis (Distant) [Homoptera: Jassidae], the vector of little leaf of brinjal. J. Res. Punjab Agric. Univ. 5:232-236.

2. Bové, J. M. 1986. Witches' broom disease of lime. FAO Plant Prot. Bull. 34:217-218.

3. Bové, J. M., M. Garnier, A. M. M. Mjeni, and A. Khayrallah. 1988. Witches' broom disease of small fruited acid lime trees in Oman: first MLO disease of citrus, p. 307-309. In Proceedings of the 10th International Organization of Citrus Virologists. Department of Plant Pathology, University of California, Riverside.

4. Bové, J. M., L. Zreik, J. L. Danet, J. Bonfils, A. M. M. Mjeni, and M. Garnier. 1993. Witches' broom disease of lime trees: monoclonal antibody and DNA probes for the detection of the MLO and the identification of a possible vector, p. 342-348. In Proceedings of the 12th International Organization of Citrus Virologists. Department of Plant Pathology, University of California, Riverside. 
5. Diabola, J. 1980. Insects of Saudi Arabia. Homoptera: Auchenorrhyncha. Fauna of Saudi Arabia, vol. 1 and 2. Pro Entomologia, Natural History Museum, and Ciba Geigy, Ltd., Basel.

6. Fitch, W. M., and E. Margoliash. 1967. Construction of phylogenetic trees. Science 155:279-284.

7. Garnier, M., L. Zreik, and J. M. Bové. 1991. Witches' broom, a lethal mycoplasmal disease of lime trees in the Sultanate of Oman and the United Arab Emirates. Plant Dis. 75:546-551.

8. Gawel, N. J., and R. L. Jarret. 1991. A modified CTAB DNA extraction procedure for Musa and Ipomoea. Plant Mol. Biol. Rep. 9:262-266.

9. Kirkpatrick, B. C., C. Smart, C. Blomquist, L. Guerra, N. Harrisson, U. Ahrens, K. H. Lorenz, B. Schneider, and E. Seemuller. 1994. Identification of MLO strain specific PCR primers obtained from 16/23S rRNA spacer sequences. IOM Lett. 3:261-262.

10. Kuske, C. R., and B. C. Kirkpatrick. 1992. Phylogenetic relationships between the Western aster yellows mycoplasmalike organism and other prokaryotes established by 16S rRNA gene sequence. Int. J. Syst. Bacteriol. 42:226-233.

11. Lim, P. O., and B. B. Sears. 1989. 16S rRNA sequence indicates that plant mycoplasmalike organisms are evolutionarily distinct from animal mycoplasmas. J. Bacteriol. 171:5901-5906.

12. Lim, P. O., and B. B. Sears. 1991. The genome size of a plant-pathogenic mycoplasmalike organism resembles those of animal mycoplasmas. J. Bacteriol. 173:2128-2130.

13. Maidak, B. L., N. Larsen, M. J. McCaughey, R. Overbeek, G. J. Olsen, K. Fogel, J. Blandy, and C. R. Woese. 1994. The Ribosomal Database Project.
Nucleic Acids Res. 22:3485-3487.

14. Murray, R. G. E., and K. H. Schleifer. 1994. Taxonomic note: a proposal for recording the properties of putative taxa of procaryotes. Int. J. Syst. Bacteriol. 44:174-176.

15. Namba, S., H. Oyaizu, S. Kato, S. Iwanami, and T. Tsuchizaki. 1993. Phylogenetic diversity of phytopathogenic mycoplasmalike organisms. Int. J. Syst. Bacteriol. 43:461-467.

16. Neimark, H., and B. C. Kirkpatrick. 1993. Isolation and characterization of full-length chromosomes from non-culturable plant pathogenic mycoplasmalike organisms. Mol. Microbiol. 7:21-28.

17. Sambrook, J., E. F. Fritsch, and T. Maniatis. 1989. Molecular cloning: a laboratory manual, 2nd ed. Cold Spring Harbor Laboratory Press, Cold Spring Harbor, N.Y.

18. Schneider, B., U. Ahrens, B. C. Kirkpatrick, and E. Seemuller. 1993. Classification of plant pathogenic mycoplasma-like organisms using restrictionsite analysis of PCR-amplified 16S rDNA. J. Gen. Microbiol. 139:519-527.

19. Seemüller, E., B. Schneider, R. Maurer, U. Ahrens, X. Daire, H. Kison, K. H. Lorenz, G. Firrao, L. Avinent, B. B. Sears, and E. Stackebrandt. 1994. Phylogenetic classification of plant-pathogenic mycoplasmas by sequence analysis of 16S rDNA. Int. J. Syst. Bacteriol. 44:440-446.

20. Subcommittee on the Taxonomy of Mollicutes (International Organization of Mycoplasmologists). 1993. Minutes of the interim meetings, 1 and 2 August 1992, Ames, Iowa. Int. J. Syst. Bacteriol. 43:394-397.

21. Weisburg, W. G., S. M. Barns, D. A. Pelletier, and D. J. Lane. 1991. 16S ribosomal DNA amplification for phylogenetic study. J. Bacteriol. 173:697703. 